Open Access

\title{
The influence of perceived behaviour control, attitude and empowerment on reported condom use and intention to use condoms among adolescents in rural Tanzania
}

\author{
Albino Kalolo ${ }^{1 *}$ and Stephen Matthew Kibusi ${ }^{2}$
}

\begin{abstract}
Background: Despite the declining trends of Human immunodeficiency virus (HIV) infection in Sub-Saharan Africa (SSA), unsafe sexual behaviours among adolescents still represent a public health challenge. It is important to understand factors acting at different levels to influence sexual behaviour among adolescents. This study examined the influence of perceived behaviour control, subjective norms, attitudes and empowerment on intention to use condoms and reported use of condoms among adolescents in rural Tanzania.

Methods: We used a questionnaire to collect data from 403 adolescents aged 14 through 19 years from nine randomly selected secondary schools in the Newala district located in the Southern part of Tanzania. The selfadministered questionnaire collected information on sexual practices and factors such as attitudes, subjective norms, perceived behaviour control and empowerment. Binary logistic regression was performed to identify factors associated with intention to use and reported use of condoms.
\end{abstract}

Results: Sexually active adolescents constituted $40.6 \%$ of the sample, among them $49.7 \%$ did not use a condom at last sexual intercourse and $49.8 \%$ had multiple sex partners. Many (85\%) of sexually active respondents had their sexual debut between the ages of 14 to 17 years. Girls became sexually active earlier than boys. Perceived behaviour control predicted intentions to use condoms ( $\mathrm{AOR}=3.059,95 \% \mathrm{Cl}$ 1.324-7.065), thus demonstrating its importance in the decision to use a condom. Empowerment (odds ratio $=3.694,95 \% \mathrm{Cl} 1.295-10.535$ ) and a positive attitude ( $\mathrm{AOR}=3.484,95 \% \mathrm{Cl} 1.132-10.72)$ predicted reported condom use, thus turning the decision to actions. Subjective norms had only indirect effects on intention and reported use of condoms.

Conclusion: The findings suggest that unsafe sex practices are prevalent among school adolescents in rural areas of Tanzania. Perceived behaviour control and positive attitudes predict intensions to use condoms whereas empowerment predicts reported condom use. The findings may imply that safe sex promotion interventions that simultaneously address socio-cognitive and ecological determinants of sexual behaviours may improve adolescents' safe sex behaviours.

Keywords: Safe sex behaviour, Rural school adolescents, Theory of planned behaviour, Empowerment model of health promotion, Tanzania

\footnotetext{
*Correspondence: kaloloa@gmail.com

'Department of Community Health, St. Francis University college of Health

and Allied Sciences, P.O.Box 175, Ifakara, Tanzania

Full list of author information is available at the end of the article
}

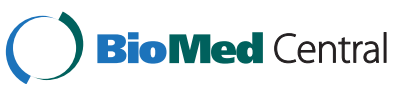

(c) 2015 Kalolo and Kibusi. Open Access This article is distributed under the terms of the Creative Commons Attribution 4.0 International License (http://creativecommons.org/licenses/by/4.0/), which permits unrestricted use, distribution, and reproduction in any medium, provided you give appropriate credit to the original author(s) and the source, provide a link to the Creative Commons license, and indicate if changes were made. The Creative Commons Public Domain Dedication waiver (http://creativecommons.org/publicdomain/zero/1.0/) applies to the data made available in this article, unless otherwise stated. 


\section{Background}

The risk of acquiring HIV infection, STIs and early or unintended pregnancy is increased by unsafe sexual behaviours [1-5]. Unsafe sexual behaviuors such as little use of condoms and having multiple sexual partners present a persistent challenge in the fight against the spread of STIs and HIV infection [3, 4, 6, 7]. Adolescents have been at the center of unsafe sexual practices and thus continue to suffer from negative consequences of the behaviours [7-9]. Statistics on the burden of HIV infection show that among the 36.9 million living with HIV /AIDS as of 2014, young people aged between 15-24 years accounted for $42 \%$ of new HIV infections [10]. SubSaharan Africa (SSA) carries $71 \%$ of the burden [11]. The burden of early or unintended pregnancy continues to grow in SSA [12].

In Tanzania, by the end of 2013, the proportion of young people aged between 15-24 years living with HIV/AIDS stood at $11.2 \%$ [13] .Yet only $43.4 \%$ of adolescents aged 15-24 years had comprehensive knowledge of HIV/AIDS including knowing that consistent use of a condom during sexual intercourse and having just one uninfected faithful partner can reduce the chance of getting the AIDS virus, knowing that a healthy-looking person can have the AIDS virus, and being able to reject the most common local misconceptions about transmission or prevention of HIV/AIDS [13, 14]. Up to $32 \%$ of the adolescent girls and $34.3 \%$ of the boys aged 15-19 years are sexually active before they reach 15 years of age. Girls in rural areas are more likely to start sex before 15 years than their counterparts in urban areas. Condom use in this group is low with only $55.7 \%$ of the adolescents reporting condom use at last higher-risk sex defined as sexual intercourse with a non-marital, noncohabiting partner [14]. Up to $1.9 \%$ of girls and $6.8 \%$ of boys have multiple sexual partners and $44 \%$ of them are either mothers or fathers by the age of 19 years [14].

To address the challenge of unsafe sexual behaviours among adolescents, countries have adopted various strategies that target adolescents in school and out of school [13-15]. School based-HIV interventions have been implemented $[1,16,17]$ and recommended for scale up as they represent an important strategy to reach children and young people in large numbers [18]. In Tanzania, to address HIV transmission among school adolescents, sexuality education and HIV prevention interventions have been included as part of the school curriculum $[14,19]$.

Despite these efforts, unsafe sexual behaviours among school adolescents are still prevalent [1, 4, 6, 16-19]. Evaluations of the school-based interventions in poorresource settings show impact of the interventions on increasing knowledge and changing attitudes towards safe sex behaviours but there is limited evidence about the impact of these interventions on actual practices of safe sexual behaviours [13, 23].

Sexual behaviour of adolescents is shaped by multiple factors [1, 4, 24] which either act at individual level such as knowledge and attitudes or those which result as a consequence of the surrounding environment (ecological factors) such as availability of condoms and policies that create favourable environment to use condoms [20, 24-26]. In an attempt to understand sexual behaviour several theories and models have been applied in past research. These theories and models have mainly been socio-cognitive [27-29] and ecological models [25]. Most of the existing evidence is devoted to isolated theories or combination of theories that target a group of factors which act at the same level and therefore they may not be sufficient to understand the complexities of the sexual behaviours among adolescents. Studies in Tanzania and elsewhere in SSA, have focused much on socio-cognitive theories alone, such as the Health Belief Model [21, 26] and the Theory of Planned Behaviour (TPB) [15, 30]. In order to understand the complexities of sexual behaviour and thereby device comprehensive programs to improve safe sexual behaviour among adolescents, there is a need for integrated approach.

The TPB is mainly a socio-cognitive theory that provides a detailed understanding of the influence of individual's attitudes, subjective norms and perceived behaviour control on the intentions to act [31]. Behavioural intentions indicate how hard people are willing to try and how much effort people plan to exert toward performance of a given behaviour. In addition, Ajzen [28] proposed that perceived behavioural control could also predict behaviour directly when behaviour is not under complete volitional control and when perceptions of control are realistic. Literature has documented the link between attitudes and sexual behaviour outcomes [32]. The influence of subjective norms on sexual behaviours is well documented [33]. Ajzen's construct of perceived behavioural control, which is similar to Bandura's [27, 34] construct of self-efficacy has also been found to impact sexual behaviour outcomes [35, 36]. This theory has been widely applied to design interventions and guide studies in safe sexual behaviours among adolescents of sub-Saharan Africa [20, 22, 30, 37-40].

The empowerment model of health promotion (EHP)[41] proposes the use of bottom up, non-directive and client centred approaches to influence individual choices regarding healthy behaviours and creation of health public policy. It supports the idea of empowering adolescents through participatory, face to face encounters and not merely by providing information but rather seeking to empower choices by building individual capacity (self-empowerment).Youth empowerment is attained through such methods as peer resistance 
trainings, peer leadership programs, life skills trainings, participation in youth led organisations or groups and the active involvement of youth in decision making on health issues affecting their lives .The model puts emphasis on the power of healthy public policy and health education in influencing healthy behaviours. The approach is seen as central to shifting from information (sermons) to empowerment thus facilitating actual performance of behaviours [41, 42]

In the present study we combined the constructs from TPB [43] and EHP[41] to study sexual behaviours of school adolescents. The constructs are combined to provide a comprehensive understanding of the factors that affect sexual practices. We postulate that socio-cognitive (individual) factors are important in decision-making to adopt safe sexual behaviour, whereas ecological factors support the execution of the decision. The TPB sheds more light on individual factors whereas the EHP helps to understand the wider ecological factors that influence sexual practices. In this study we did not aim to asses any specific intervention or assessing the validity of the two theories but the study findings may offer a challenge to the existing safe sex interventions, specifically so for interventions targeting school adolescents.

This study aimed to describe the factors influencing sexual behaviours among adolescents residing in generally rural areas of Tanzania using a framework that combines socio-cognitive and ecological constructs. Specifically we aimed to (1) determine the extent of unsafe sexual practices of adolescents (2) determine the correlation between the predictor variables i.e., perceived behaviour control, subjective norms, attitudes and empowerment (3) determine the influence of perceived behavioural control, attitudes and empowerment on intention to use condoms and (4) determine the influence of perceived behavioural control, attitudes and empowerment on reported use of condoms.

\section{Methods}

\section{Study settings}

This study was conducted from May to August 2010 in Newala district located in the Mtwara region of Tanzania. At the time of data collection, the district counted a population of 183,930 with 84,914 men and 99,016 women and it was geographically divided into 3 divisions, 21 wards and 155 registered villages. The district had 26 secondary schools with an estimate of 8169 students. The current population stands at 205,492 (2012 census) with a growth rate of $1.2 \%$ and the district has further been divided to include 5 divisions, 28 wards and 155 registered villages [44]. The HIV prevalence in Tanzania was $5.7 \%$ at the time we conducted the study and it has been recorded to decline especially in young people aged 15-24 years [45]. The prevalence of HIV infection in the district stood at $3.1 \%$ (antenatal care proxy) [46]. Secondary education in
Tanzania consists of six years of schooling divided into two levels of four years (Ordinary level) and two years (Advanced level) as described in other studies $[19,26]$. Only Ordinary level students were included in the present study.

\section{Study design}

This study relied on a cross-sectional analysis of data collected from school adolescents of the Newala district. The essential features of the study include: (1) sampling of the secondary schools located in the district (2) Sampling the adolescents to participate in the study (3) Data collection using a self-administered questionnaire and (4) Conducting analysis of the collected data.

\section{Study population and sampling procedures}

Sampling was done using multistage cluster sampling procedure. Twenty six O-level secondary schools were considered. Thereafter schools were stratified according to geographical divisions and nine schools were selected, three from each of the divisions. The schools consisted of a total population of 4392 students with 2126 males and 2266 females.

Within selected schools, we intended to invite for interview all students in all classes aged between 14 through 19 years. In this study, 403 study students filled a selfadministered questionnaire. This sample size was adequate as it exceeded the calculated sample size of 389 students with an assumption of $80 \%$ power, $42 \%$ of youth who use condoms in previous studies [8] and an estimated error margin of 0.05 .

\section{Data collection instrument and procedures}

Primary data were collected using a pre-tested selfadministered questionnaire. The questionnaire was designed after considering recommendations from previous researchers on TPB $[47,48]$ and the ecological perspectives $[49,50]$.The questionnaire collected information related to socio-demographic variables, sexual practices, knowledge on safe sex behaviours, attitudes, subjective norms and behaviour control. The questions were presented in one of the three formats: yes or no, Likert scale questions with responses ranging from three (agree, uncertain, disagree) or five categories (totally agree, agree, uncertain, disagree, and totally disagree) responses. The questionnaire was administered within the classroom by a trained research assistant. Research assistants were introduced to students by a teacher who later on was asked to leave the classroom to give students more freedom and privacy. Participation was voluntary and the questionnaire was anonymously filled and participants had an opportunity to withdraw at any point without being asked any questions The questionnaire was translated from English to Kiswahili (the lingua 
franca in Tanzania) to facilitate understanding of the items by the adolescents.

\section{Variables and measures}

Sexual behaviours were measured by responses from questionnaire presented in binary (yes/no) or multiple responses depending on the variable measured. Behavioural variables consisted of age at sexual debut (14 years of age or younger, 15 years of age or older); number of lifetime sex partners (only one, two, three to five, six or more); use of condom in last risky sex("yes," used condom; "no," did not use condom). Intention to use condoms was assessed by a statement "I intend to use a condom next time I have sexual intercourse" ("yes," intends to use a condom; "no," does not have intention to use a condom).Behavioural variable were considered as dependent variables for this study.

The independent variables were a combination of attitudes, subjective norms, perceived behaviour control and empowerment constructs that originate from $\mathrm{TPB}$ and EHP.

Attitudes: defined as a person's overall evaluation of behaviours related to and performing safe sex (consistent condom use during penetrative sexual intercourse, reduction of sex partners and delayed age at first sex (and secondary sexual abstinence). These were assessed by four items on one's evaluation and feelings on the benefits of safe sex (two items) and related sub-behaviours of practising safe sex (two items) (e.g. Condoms protect against HIV infection). The expected response were Likert scale 1-5 (from totally agree to totally disagree).

Subjective Norms: refer to belief that specific referents think that the school adolescents should perform safe sex to protect themselves from sexually transmitted infections, HIV infection and unwanted pregnancies and the individual's motivation to comply with referents. In this study, important referent was defined to mean parents, friends, teachers and religious leaders. Subjective norms were assessed by using ten items categorized as peer pressure from friends towards or against safe sex behaviours. We used statements such as "I agree with my religious leaders' opinion that I should not use condoms when having sexual intercourse or I agree with the opinion of my friends that I should use condoms when having sex". The expected responses were Likert scale 1-5 (from totally agree to totally disagree).

Perceived behavior control: refer to adolescent's perceptions of his/her ability to practice safe sex. In line with Ajzen's work [47], perceived behavioral control was assessed with two components: perceived self-efficacy (close to Bandura's [27] construct of self-efficacy, which has stronger path with intention than the behaviour) and perceived controllability (that has stronger path or link with behaviour than intention. We used statements such as "It is mostly up to me whether I decide to use a condom or not". The expected responses were Likert scale 1-5 (from totally agree to totally disagree).

Empowerment: refers to adolescent's ability to taking a lead in safe sex promotion in school and/or out of school and control of the surrounding environment in the search for practicing health life styles, i.e., safe sex behaviors. We conceptualized empowerment as a two way process that involve conscious raising (self-empowerment) and at presence (or creation) of enabling environment to support performance of safe sexual behaviors. Empowerment was measured by asking adolescents' involvement participatory health promotion programs in and out of school environment. The questions focused on their participation in life skills training sessions on sexual and reproductive health, peer education, music and sports festivals with safe sex promotion themes. In addition, adolescents were asked about their experiences with user friendliness of sexual and reproductive health services in their area and the policies that promote safe sexual behaviours. Their responses to these questions were binary i.e., "yes" or "no".

\section{Data analysis}

Guided by our conceptual framework (Fig. 1), we used Statistical package for Social sciences (SPSS) version 15 to analyse the collected data. Descriptive analysis of the background information was performed in order to get the initial picture of the studied population before progressing to detailed analysis. Age was operationalized as age in years and was split into two categories, distinguishing young adolescents (14-16 years) from older adolescents (17-19 years).Exploratory factor analysis using a principal components approach (PCA) was used to reduce the items to latent constructs and to obtain scales. Only items with a reliability coefficient $(\alpha)$ of at least 0.60 were considered acceptable [51]. Bivariate correlation (Pearson's correlation coefficient $(r)$ was obtained in order to see how outcome variables relate to the scales obtained and also the background characteristics in the study. Furthermore, a diagnostic independent $t$-test was applied to check how the outcome variables relate to the obtained scales before conducting multivariate analysis. We employed logistic regression to determine the predictors of safe sex practices because our dependent variables were dichotomous. A backward selection procedure was applied to determine which independent (predictor) variables together were good predictors of each outcome in determining intention to practice safe sex and reported actual safe sex behaviour. The overall variance inflation factor (VIF) of the logistic regression model was 1.02, thus, indicating low degree of multicollinearity.

Since one of our major aims was to advance knowledge on condom use, in this study we considered only two outcome variables for regression analysis: (1) intention to 


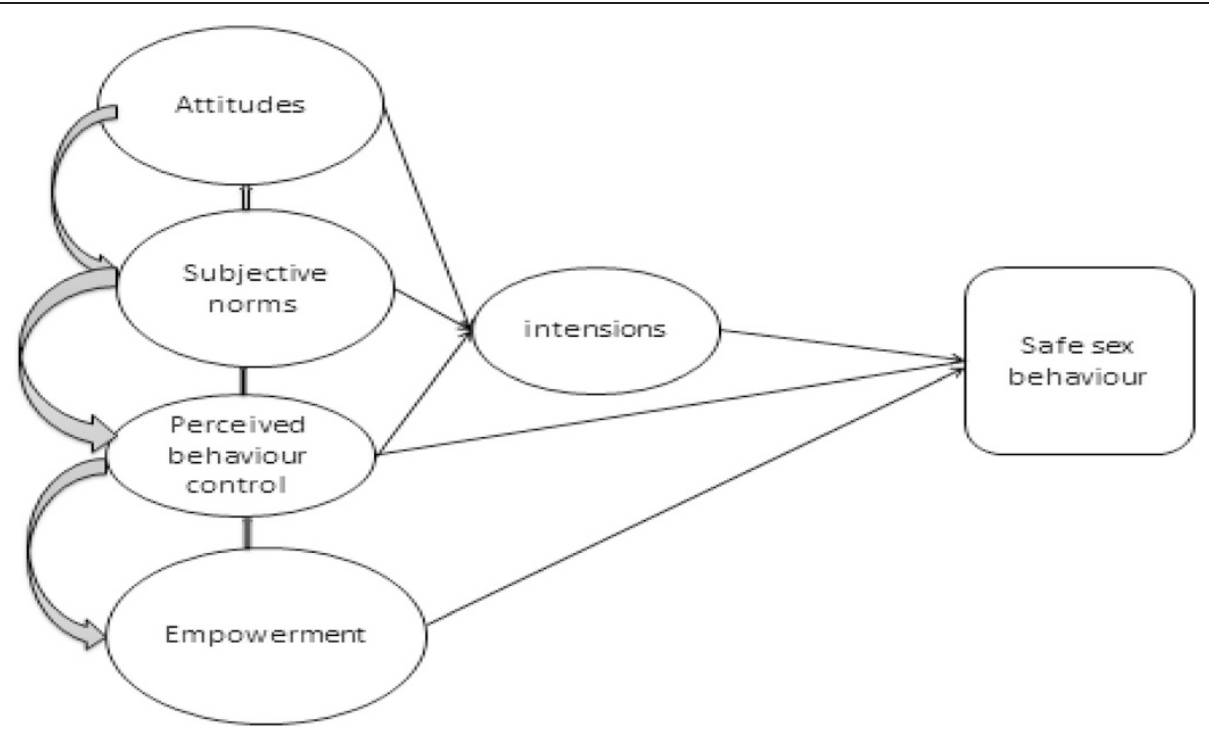

Fig. 1 Theoretical model for this study (Adopted from Ajzen I [27] TPB constructs with addition of the empowerment component)

engage in safe sex, that is, intention to use condoms during intercourse in the future and (2) reported actual safe sex behaviour (for the sexually active youth) that is use of condoms during the last sexual intercourse. The constructs from TPB and EHP were taken as predictors of safe sex behaviours.

\section{Ethical consideration}

Ethical clearance was provided by the National Institute of Medical research (NIMR) Tanzania. After the permission from the District Executive Director, the District Education Officer and the Head Masters of the participating schools were asked for informed consent to permit the students to take part in the study. After being informed of the study, students were requested to sign for consent.

\section{Results}

We present the results in accordance to respondents' socio-demographics, sexual behaviours and determinants of intention to use condoms and reported use of condoms.

\section{Socio-demographics}

Four hundred and three participants were recruited in this study of whom $50.4 \%$ (203) were males and $49.6 \%$ (200) were females. Two hundred and seventy seven (69 \%) were in the age group 17-19 years. Although the mean age was $17.1 \pm 1.44$ years, males had slightly higher mean age $(17.23 \pm 1.40)$ than females $(16.98 \pm 1.47)$. The study participants were predominantly Muslims (87.1\%). Table 1 provides details of socio-demographic characteristics.

\section{Sexual behaviours}

One hundred sixty four (40.6\%) of the participants were sexually active. More males (57.3 \%) than females (42.7\%) were sexually active. Approximately eighty five percent of sexually active students reported to have started sex at age between 14 and 17 years and only $15.3 \%$ started at an age less than 14 years. The majority of those who reported to be sexually active adolescents up to $84 \%$ of them had a sexual encounter within 12 months prior to the survey.

Adolescents who reported that they had not used condoms at the last sexual intercourse were 78 (50.3\%) while those who used condoms were $49.7 \%$. There was no difference between males and females on the status

Table 1 Distribution of respondents by socio-demographic characteristics ( $N=403$ )

\begin{tabular}{ll}
\hline Socio-demographics & Frequency (\%) \\
\hline Sex & \\
Female & $203(50.4 \%)$ \\
Male & $200(46.9 \%)$ \\
Age (years) & \\
$14-16$ & $126(31 \%)$ \\
$17-19$ & $277(69 \%)$ \\
Mean (Males) $=17.23 \pm 1.40$ & \\
Mean (Females) $=16.98 \pm 1.47$ & \\
Mean (Total) $=17.1 \pm 1.44$ & \\
Religion & \\
Moslems & $351(87.1 \%)$ \\
Christian (Catholics) & $29(6.9 \%)$ \\
Christian (others) & $23(6 \%)$ \\
\hline
\end{tabular}


of reported use of condoms at last sex $(p=0.284)$. Also, there was no significant difference between reported use of condoms among respondents with a single partner and those with multiple sex partners (Table 2).

The majority of adolescents (77\%) in our sample indicated that they intent to use condoms in the future. There was no statistically significant difference between males and females on intention to use condoms in the future $(p=0.148)$. Two hundred and fifteen (70\%) adolescents aged 17-19 indicated that they intend to use condoms in the future, however there was no statistical significant difference with their counterparts (less than 17 years) $(p=0.266)$. Among sexually active adolescents, $78.7 \%$ indicated future intensions to use condoms but there was no significant difference between current condom users and non-users on intentions to use condoms in the future $(p=0.071)$

Table 2 Distributions of sexual behaviours and social demographics

\begin{tabular}{|c|c|c|c|c|}
\hline Sexually active (regularly active) & Yes & No & Total & $P$-value \\
\hline \multicolumn{5}{|l|}{ Gender } \\
\hline Male & $57.30 \%$ & $42.20 \%$ & $50.40 \%$ & \\
\hline Female & $42.70 \%$ & $57.80 \%$ & $49.60 \%$ & 0.23 \\
\hline Total (N) & 164 & 239 & 403 & \\
\hline \multicolumn{5}{|l|}{ Age (years) } \\
\hline $14-16$ & $15.20 \%$ & $43.20 \%$ & $31.80 \%$ & 0.266 \\
\hline $17-19$ & $84.80 \%$ & $56.80 \%$ & $68.20 \%$ & \\
\hline Total (N) & 164 & 239 & 403 & \\
\hline Number of lifetime sex partners ${ }^{*}$ & Yes & No & Total & \\
\hline One & $49.30 \%$ & $55 \%$ & $52 \%$ & 0.019 \\
\hline Two or more & $50.70 \%$ & $45 \%$ & $48 \%$ & \\
\hline Total (N) & 81 & 83 & 164 & \\
\hline Condom use at last sex ${ }^{*}$ & Yes & No & Total & \\
\hline \multicolumn{5}{|l|}{ Gender } \\
\hline Male & $62.80 \%$ & $53.80 \%$ & $58 \%$ & \\
\hline Female & $37.70 \%$ & $46.20 \%$ & $42 \%$ & 0.284 \\
\hline Total (N) & 81 & 83 & 164 & \\
\hline Intention to use condoms & Yes & No & Total & \\
\hline \multicolumn{5}{|l|}{ Gender } \\
\hline Female & $50.90 \%$ & $41.20 \%$ & $51.1 \%$ & 0.148 \\
\hline Male & 49.1 & 58.8 & $48.90 \%$ & \\
\hline Total (N) & 306 & 97 & 403 & \\
\hline \multicolumn{5}{|l|}{ Sexually activity (past 12 months) } \\
\hline Female & $43.47 \%$ & $46.15 \%$ & $43.90 \%$ & 0.45 \\
\hline Male & $56.53 \%$ & $53.85 \%$ & 56.10 & \\
\hline Total & 138 & 26 & 164 & \\
\hline
\end{tabular}

\section{Determinants of safe sex behaviours}

Results of the binary analysis are presented in Table 3. Only perceived behaviour control showed a significant positive correlation with attitudes $(r=0.110, p<0.05)$.

Results in Table 4 show that empowerment was significantly associated with reported condom use $(\mathrm{t}=-2.348$, $p=0.02$ ). Perceived behaviour control was significantly associated with intention to use condoms $(\mathrm{t}=-5.813$, $p=0.000)$ as seen in Table 5 .

Binary logistic regression results in Table 6 indicated that perceived behaviour control predicted intention to use condoms (AOR = 3.059, $95 \%$ CI 1.324-7.065), which means, adolescents had a strong belief that they will use condoms in the future if they have sex. The results in in Table 7 indicate that empowerment $(\mathrm{AOR}=3.694, \mathrm{CI}$ 1.295-10.535) and positive attitude toward the use of condom $(\mathrm{AOR}=3.484, \mathrm{CI}=1.132-10.72)$ were significantly associated with reported actual use of condoms.

\section{Discussion}

While a number of studies have been reported on adolescent sexual behaviour in Tanzania and around the Africa region, most were based on one theoretical model in understanding sexual behaviour. In the current study, an integrated approach to assessing sexual behaviour was sought by using both theoretical approaches that look at the individual and those which focus on the ecological environment of the adolescents residing in mostly rural areas of Tanzania. Specifically, this study investigated the practices of safe sexual behaviours among adolescents and the factors that predict intension to use condoms and reported actual use of condoms.

The results show that $40.6 \%$ adolescents were sexually active. This finding is in concordance with existing evidence in other countries of around SSA [1,52] A nationally representative study in Nigeria reported that only a fifth of adolescents (18\% males; $22 \%$ females) were sexually active by the age of 19 years [53]. We also found that $49.8 \%$ of sexually active youths had already had multiple sexual partners with females reporting more partners than males $(p=0.019)$. This proportion is

Table 3 Correlation of independent variables $(N=403)$

\begin{tabular}{lllll}
\hline $\begin{array}{l}\text { Pearson } \\
\text { correlation }\end{array}$ & Empowerment & $\begin{array}{l}\text { Subjective } \\
\text { norm }\end{array}$ & $\begin{array}{l}\text { Perceived } \\
\text { behaviour } \\
\text { control }\end{array}$ & attitude \\
\hline $\begin{array}{l}\text { Empowerment } \\
\begin{array}{l}\text { Subjective } \\
\text { norm }\end{array}\end{array}$ & .1 & 1 & & \\
$\begin{array}{l}\text { Perceived } \\
\text { behaviour } \\
\text { control }\end{array}$ & .075 & .003 & 1 & \\
attitudes & .080 & .015 & $.110(* *)$ & 1 \\
\hline
\end{tabular}

** $p \leq 0.05$ 
Table 4 Relationship between reported condom use with mean sum scores subjective norms, perceived behaviour control, attitudes and empowerment

\begin{tabular}{lcccc}
\hline Variable mean scores & \multicolumn{2}{l}{$\begin{array}{l}\text { Condom use at last sex } \\
(\%)(N=164)\end{array}$} & & $p$-value \\
\cline { 2 - 4 } & Yes & No & & \\
\hline Subjective norm & 20.27 & 208 & -1.105 & 0.296 \\
Perceived behavior control & 28.18 & 28.5 & -0.454 & 0.651 \\
Empowerment & 22.9 & 24.9 & -2.348 & 0.021 \\
Attitudes & 10.4 & 11.23 & -1.451 & 0.149 \\
\hline
\end{tabular}

higher than what was reported in Tanzania by another similar study [8]which reported a $15 \%$ of sexually active adolescents had multiple partners. The setting being mostly rural and ways in which questions were designed in the present study could explain the difference observed. However, another study in rural Tanzania found that up to $42 \%$ of sexually active adolescents had multiple sexual partners [6]. High prevalence of multiple sexual partners among sexually active adolescents have been reported elsewhere $[6,45]$ and in most cases, males reported more sexual partners than females $[6,8]$

In the present study, it was also found that the prevalence of reported condom use stands at $50.30 \%$ unlike existing evidence that shows that condom use can be as high as $73 \%$ [1]. The low proportion of adolescents who reported to have used condom in the last sex to comparable studies might be due to factors such as negotiation skills to use a condom or unavailability of condoms when needed. Exavery and colleagues [6] found that $39 \%$ of adolescents in rural Tanzania used condoms at last sex and attributed the lack of condom use to inequalities in condom availability as well as remoteness of some places in rural areas. Similar findings were reported in South Africa by Eaton and colleagues [4] that unavailability of condoms hindered youth to use condoms. Moreover, variation in cultural factors such as, gender roles and religion and differences of access to information, communication and education, might have contributed [54]

Table 5 Relationship between intension to use condoms in the future with mean sum scores subjective norms, perceived behaviour control, attitudes and empowerment

\begin{tabular}{lccrr}
\hline Variable mean score & \multicolumn{2}{l}{$\begin{array}{l}\text { Intention to use condoms } \\
\text { in the future }(N=403)\end{array}$} & & t -value \\
\cline { 2 - 3 } & Yes & No & & \\
\hline Subjective norm & 20.54 & 19.84 & 1.854 & 0.064 \\
Perceived behavior control & 28.11 & 31.06 & -5.813 & 0.000 \\
Empowerment & 24.2 & 24.2 & -0.139 & 0.890 \\
Attitudes & 11.05 & 11.66 & -1.382 & 0.160 \\
\hline
\end{tabular}

Table 6 Crude and adjusted models for intentions to use condoms $(N=403)$

\begin{tabular}{lllllll}
\hline & COR & $\begin{array}{l}P- \\
\text { value }\end{array}$ & $\begin{array}{l}95 \% \mathrm{Cl} \\
\text { for OR }\end{array}$ & AOR & $\begin{array}{l}P- \\
\text { value }\end{array}$ & $\begin{array}{l}95 \% \mathrm{Cl} \\
\text { (AOR }\end{array}$ \\
\hline Empowerment & 0.923 & 0.808 & $0.484-$ & 3.059 & 0.009 & $1.324-$ \\
& & & 1.761 & & 7.065 \\
Perceived behaviour & 2.682 & 0 & $1.653-$ & & & \\
control & & & 4.350 & & & \\
Attitudes & 1.275 & 0.309 & $0.798-$ & & & \\
& & & 2.035 & & & \\
Knowledge & 0.987 & 0.973 & $0.455-$ & & & \\
& & & 2.139 & & & \\
Subjective norm & 0.932 & 0.769 & $0.52-$ & & & \\
& & & 1.491 & & & \\
\end{tabular}

Correlation between predictor variables showed that only perceived behaviour control and attitudes are correlated but the correlation was not higher than $70 \%$. This finding indicates that other predictor variables were different from each other .It is also not surprising that perceived behaviour control correlates with attitudes as previous studies showed that perceived behaviour control may be similar to affective attitude [55]

We found that the reported actual use of condoms as an outcome variable was strongly determined by empowerment and attitudes. The finding explains the role of empowerment and positive attitudes of turning intentions into actions, but it might also mean that adolescents who are empowered and have positive attitudes towards condoms found it desirable to report that they used condoms in the last sex even when they did not (social desirability bias) as is always the case in self report data in sensitive topics [56].

In line with prior research that has indicated intention to use condoms to better predicted by perceived behaviour control than other TPB constructs and empowerment [30,37], our findings then offer further support to the notion that intention to condom use is determined by perception of control of an individual towards condom

Table 7 Crude and adjusted for reported condom use among sexually active adolescents $(N=155)$

\begin{tabular}{|c|c|c|c|c|c|c|}
\hline & COR & $\begin{array}{l}P- \\
\text { value }\end{array}$ & $\begin{array}{l}95 \% \mathrm{Cl} \\
\text { for COR }\end{array}$ & $\mathrm{AOR}$ & $\begin{array}{l}P \text { - } \\
\text { value }\end{array}$ & $\begin{array}{l}95 \% \mathrm{Cl} \\
\text { for } \mathrm{AOR}\end{array}$ \\
\hline Empowerment & 2.336 & 0.044 & $\begin{array}{l}1.023- \\
5.332\end{array}$ & 3.694 & 0.015 & $\begin{array}{l}1.295- \\
10.535\end{array}$ \\
\hline $\begin{array}{l}\text { Perceived } \\
\text { behaviour control }\end{array}$ & 0.978 & 0.945 & $\begin{array}{l}0.517- \\
1.848\end{array}$ & 3.484 & 0.029 & $\begin{array}{l}1.132- \\
10.72\end{array}$ \\
\hline Attitudes & 0.586 & 0.111 & $\begin{array}{l}0.304 \\
-1.131\end{array}$ & 0.196 & 0.01 & \\
\hline Knowledge & 1.965 & 0.159 & $\begin{array}{l}0.768 \\
-5.027\end{array}$ & & & \\
\hline Subjective norm & 1.054 & 0.87 & $\begin{array}{l}0.560- \\
1.983\end{array}$ & & & \\
\hline
\end{tabular}


use [57]. This might also mean that perceived behaviour control has a great importance on decision making to perform a certain behaviour whereas empowerment and positive attitudes appear to be important in turning intentions into viable actions. As such, future studies assessing condom use among adolescents in rural Tanzania can further investigate the combined effect of empowerment and attitudes on condom use using more rigorous designs.

Although this study was set to generate important evidence with regards to sexual behaviours of adolescents, some limitations need to be acknowledged. As a crosssectional study, we cannot use the findings for causal relationships between variables. Response bias and social desirability bias was another limitation as data was collected through self-administered questionnaires.

Our findings may imply that health promotion programs that use a combined framework in designing safe sex promotion might have more impact than those that focus on Knowledge-Attitude-Practice or TPB socio-cognitive components alone. However, more rigorous studies might help to establish the effect and added value of the combined framework on safe sexual behaviours in these settings

\section{Conclusion}

This study represents an initial attempt to examine the role of combined framework that takes into account sociocognitive and ecological factors to study sexual behaviours among adolescents in rural Tanzania. Our findings suggest that a considerable proportion of adolescents in the study setting practice unsafe sexual behaviours. Perceived behaviour control predicted intentions to use condoms while empowerment and attitudes predicted reported condom use. Subjective norms had only indirect effects on intention and reported use of condoms. Application of combined framework that takes into account socio-cognitive factors as well as an ecological component can add value to safe sex promotion interventions. Moreover, community empowerment based on participatory frameworks that base on critical consciousness rising and influence on public health policy can add a value and support safe sex behaviour interventions that are aimed at penetrating community networks.

\section{Abbreviations \\ AOR: Adjusted Odds ratio; Cl: Confidence Interval; COR: Crude Odds ratio; EHP: Empowerment Model of Health Promotion; HIV: Human Immunodeficiency Syndrome; NIMR: National Institute for Medical Research; PCA: Principal Component Analysis; SPSS: Statistical package for Social Sciences; SSA: Sub-Saharan Africa; TPB: Theory of Planned Behaviour.}

\section{Competing interests}

The authors declare that they have no competing interests.

\section{Authors' contribution}

AK conceived the study design and collected data, carried out analysis and drafted the manuscript. SMK carried out the analysis and revised final draft of the manuscript. All authors read and approved the final manuscript.

\section{Acknowledgements}

We would like to express our gratitude to Newala district authority, Teachers and students in the participating schools. Funding for this study was provided to the first author through the Ford Foundation International fellowship program (IFP). We are thankful to our research assistants for assisting us in the data collection. Special thanks go to Anja Krumeich and Michelene Chenault from the Faculty of Health, Medicine and Life sciences, Maastricht University for their helpful critique on the conceptual framework and analytical approach.

\section{Author details}

${ }^{1}$ Department of Community Health, St. Francis University college of Health and Allied Sciences, P.O.Box 175, Ifakara, Tanzania. ${ }^{2}$ School of Nursing and Public Health, College of Health Sciences, The University of Dodoma, P.O. Box 395, Dodoma, Tanzania.

Received: 3 May 2015 Accepted: 10 November 2015

Published online: 13 November 2015

\section{References}

1. Kaaya SF, Flisher AJ, Mbwambo JK, Schaalma H, Aarø LE, Klepp K-I. A review of studies of sexual behaviour of school students in sub-Saharan Africa. Scand J Public Health. 2002;30(2):148-60.

2. Poudel KC, Tandukar KP, Nakahara S, Yasuoka J, Jimba M. Knowing the Consequences of Unprotected Sex with Seroconcordant Partner Is Associated with Increased Safer Sex Intentions among HIV-positive Men in Kathmandu. Nepal J Health Popul Nutr. 2011;29(3):191-9.

3. Mudhovozi P. Unsafe Sexual Behavior, Reasons for Consequences and Preventive Methods Among College Students. J Psychol Afr. 2011;21(4):573-5.

4. Eaton L, Flisher AJ, Aarø LE. Unsafe sexual behaviour in South African youth. Soc Sci Med 1982. 2003:56(1):149-65.

5. Okonofua FE, Odimegwu C, Ajabor H, Daru PH, Johnson A. Assessing the Prevalence and Determinants of Unwanted Pregnancy and Induced Abortion in Nigeria. Stud Fam Plann. 1999;30(1):67-77.

6. Exavery A, Lutambi AM, Mubyazi GM, Kweka K, Mbaruku G, Masanja H. Multiple sexual partners and condom use among 10-19 year-olds in four districts in Tanzania: What do we learn? BMC Public Health. 2011; 11(1):490.

7. Twa-Twa JM, Oketcho S, Siziya S, Muula AS. Prevalence and correlates of condom use at last sexual intercourse among in-school adolescents in urban areas of Uganda. East Afr J Public Health. 2008;5(1):22-5.

8. Kazaura MR, Masatu MC. Sexual practices among unmarried adolescents in Tanzania. BMC Public Health. 2009;9(1):373.

9. Kotchick BA, Shaffer A, Forehand R, Miller KS. Adolescent sexual risk behavior: a multi-system perspective. Clin Psychol Rev. 2001;21(4):493-519.

10. UNAIDS. MDG 6: 15 YEARS, 15 LESSONS OF HOPE FROM THE AIDS RESPONSE [Internet]. UNAIDS; 2014. Available from: http://www.unaids.org/sites/default/ files/media_asset/20150714_FS_MDG6_Report_en.pdf

11. Joint United Nations Program on HIV/AIDS. Global report:UNAIDS report on Global AIDS epidemic. 2013;p.12-29.

12. Hubacher D, Mavranezouli I, McGinn E. Unintended pregnancy in subSaharan Africa: magnitude of the problem and potential role of contraceptive implants to alleviate it. Contraception. 2008;78(1):73-8.

13. Scott-Sheldon LAJ, Walstrom P, Harrison A, Kalichman SC, Carey MP. Sexual Risk Reduction Interventions for HIV Prevention among South African Youth: A Meta-Analytic Review. Curr HIV Res. 2013:11(7):549-58.

14. Renju J, Nyalali K, Andrew B, Kishamawe C, Kimaryo M, Remes P, et al. Scaling up a school-based sexual and reproductive health intervention in rural Tanzania: a process evaluation describing the implementation realities for the teachers. Health Educ Res. 2010;25(6):903-16.

15. Mkumbo K, Schaalma H, Kaaya S, Leerlooijer J, Mbwambo J, Kilonzo G. The application of Intervention Mapping in developing and implementing school-based sexuality and HIV/AIDS education in a developing country context: The case of Tanzania. Scand J Public Health. 2009;37(2 suppl):28-36.

16. Aarø LE, Mathews C, Kaaya S, Katahoire AR, Onya H, Abraham C, et al. Promoting sexual and reproductive health among adolescents in southern and eastern Africa (PREPARE): project design and conceptual framework. BMC Public Health. 2014;14(1):54.

17. Wamoyi J, Mshana G, Mongi A, Neke N, Kapiga S, Changalucha J. A review of interventions addressing structural drivers of adolescents' sexual and reproductive health vulnerability in sub-Saharan Africa: implications for sexual health programming. Reprod Health. 2014;11(1):88. 
18. Dick B, Ferguson J, Ross DA. Preventing HIV/AIDS in young people. A systematic review of the evidence from developing countries. Introduction and rationale. World Health Organ Tech Rep Ser. 2006;938:1-13. discussion 317-41.

19. Mkumbo KA. Content analysis of the status and place of sexuality education in the national school policy and curriculum in Tanzania. Educ Res Rev. 2009;4(12):616-25.

20. Protogerou C, Flisher AJ, Wild LG, Aarø LE. Predictors of condom use in South African university students: a prospective application of the theory of planned behavior. J Appl Soc Psychol. 2013;43:E23-36.

21. Katikiro E, Njau B. Motivating Factors and Psychosocial Barriers to Condom Use among out-of-School Youths in Dar es Salaam, Tanzania: A Cross Sectional Survey Using the Health Belief Model. Int Sch Res Not. 2012; 2012:e170739.

22. Hendriksen ES, Pettifor A, Lee S-J, Coates TJ, Rees HV. Predictors of Condom Use Among Young Adults in South Africa: The Reproductive Health and HIV Research Unit National Youth Survey. Am J Public Health. 2007:97(7):1241-8.

23. Fonner VA, Armstrong KS, Kennedy CE, O'Reilly KR, Sweat MD. School Based Sex Education and HIV Prevention in Low- and Middle-Income Countries: A Systematic Review and Meta-Analysis. PLoS One. 2014;9(3), e89692.

24. Aoro L, Schaalma H, Amstrom A. Social cognition models and social cognition theory : Predicting sexual and reproductive behaviour among adolescents in Subsaharan Africa. In: Klepp K-I, Flisher AJ, Kaaya SF, editors. Promoting Adolescent, Sexual and reproductive Health in East and Southern Africa. Cape Town, South Africa: HSRC PRESS; 2008. p. 37-55.

25. Salazar LF, Bradley ELP, Younge SN, Daluga NA, Crosby RA, Lang DL, et al. Applying ecological perspectives to adolescent sexual health in the United States: rhetoric or reality? Health Educ Res. 2010;25(4):552-62.

26. Njau B, Mwakalo V, Mushi D. Correlates of Use of Condoms Among Sexually Active Youth in Southern Highlands. Tanzania SAGE Open. 2013;3(2): 2158244013491406.

27. Bandura A. Social foundations of thought and action: A social cognitive theory. Prentice-Hall, Inc: Englewood Cliffs, NJ, US; 1986. 617 p.

28. Ajzen I. The Theory of Planned Behavior. Organ Behav Hum Decis Process. 1991;50(2):179-211.

29. Fishbein M, Aizen I. Belief, Attitudes, Intention and Behaviour: an Introduction to Theory and Research. Addison-Wesley Pub;1975.

30. Lugoe W, Rise J. Predicting Intended Condom Use among Tanzanian Students using the Theory of Planned Behaviour. J Health Psychol. 1999;4(4):497-506.

31. Ajzen I. From Intentions to Actions: A Theory of Planned Behavior. In: Kuhl PDJ, Beckmann DJ, editors. Action Control [Internet]. Springer Berlin Heidelberg; 1985 [cited 2015 Mar 5]. p. 11-39. Available from: http://link. springer.com/chapter/10.1007/978-3-642-69746-3_2

32. White KM, Terry DJ, Hogg MA. Safer Sex Behavior: The Role of Attitudes, Norms, and Control Factors. J Appl Soc Psychol. 1994;24(24):2164-92.

33. Sacolo HN, Chung MH, Chu H, Liao YM, Chen CH, Ou KL, et al. High Risk Sexual Behaviors for HIV among the In-School Youth in Swaziland: A Structural Equation Modeling Approach. PLoS ONE. 2013;8(7).

34. Bandura A. A social cognitive approach to the exercise of control over AIDS infection. In: DiClemente RJ, editor. Adolescents and AIDS A generation in jeopardy. Sage Publications Inc, Newbury Park, Califonia. 1992;p.89-116

35. Jemmott JB, Heeren GA, Ngwane Z, Hewitt N, Jemmott LS, Shell R, et al. Theory of planned behaviour predictors of intention to use condoms among Xhosa adolescents in South Africa. AIDS Care. 2007;19(5):677-84.

36. Molla M. Nordrehaug Åstr $\oslash \mathrm{m}$ A, Brehane Y. Applicability of the theory of planned behavior to intended and self-reported condom use in a rural Ethiopian population. AIDS Care. 2007;19(3):425-31.

37. Schaalma H, Aarø LE, Flisher AJ, Mathews C, Kaaya S, Onya H, et al. Correlates of intention to use condoms among Sub-Saharan African youth: the applicability of the theory of planned behaviour. Scand J Public Health. 2009;37 Suppl 2:87-91.

38. Kaaya SF, Mukoma W, Flisher AJ, Klepp K. School-based sexual health interventions in sub-Saharan Africa: A review. Soc Dyn. 2002;28(1):64-88.

39. Denka M, Östergren PO, Ekman B, Agardh A. Inconsistent condom use among Ugandan university students from a gender perspective: a crosssectional study | Mehra [Internet]. 2014 [cited 2015 Oct 19]. Available from: about:reader?url = http\%3A\%2 F\%2Fwww.globalhealthaction.net\%2Findex. php\%2Fgha\%2Farticle\%2Fview\%2F2294.

40. Eggers SM, Taylor M, Sathiparsad R, Bos AE, de Vries H. Predicting safe sex: Assessment of autoregressive and cross-lagged effects within the Theory of Planned Behavior. J Health Psychol. 2015;20(11):1397-404.
41. Tones K, Tilford S. An empowerment model of health promotion. In: Tones K, Tilford S, editors. Health Promotion: Effectiveness, Efficiency and Equity, 3rd edn. Nelson Thornes Ltd, Cheltenham. 2001;49-55.

42. Hagquist C, Starrin B. Health Education in Schools-From Information to Empowerment Models. Health Promot Int. 1997;12(3):225-32.

43. Ajzen I. The Theory of Planned Behaviour. Organ Behav Hum Decis Process. 1991;50:179-211.

44. United Republic of Tanzania. Population Distribution by Age and Sex. National Bureau of Statistics,Dar es Salaam. 2013;p.199.

45. Tanzania Commission for AIDS (TACAIDS),Zanzibar AIDS Commission (ZAC) National Bureau of Statistics (NBS), Office of the Chief Government Statistician (OCGS), ICF International. Tanzania HIV/AIDS and Malaria Indicator Survey 2011-12.TACAIDS,ZAC,NBS,OCGS, ICF International; 2013.

46. Newala District Council(NDC). Comprehensive Council Health Plan 2009/ 2010. NDC; 2010

47. Ajzen I. Perceived Behavioral Control, Self-Efficacy, Locus of Control, and the Theory of Planned Behavior1. J Appl Soc Psychol. 2002;32(4):665-83.

48. Francis J, Eccles MP, Johnston M, Walker AE, Grimshaw JM, Foy R, Kaner EFS, Smith L, Bonetti D. Constructing questionnaires based on the theory of planned behaviour: A manual for health services researchers [Internet] 2004 [cited 2015 Mar 5]. Available from: http://openaccess.city.ac.uk/1735/1/ TPB\%20Manual\%20FINAL\%20May2004.pdf.

49. McLeroy KR, Bibeau D, Steckler A, Glanz K. An Ecological Perspective on Health Promotion Programs. Health Educ Behav. 1988;15(4):351-77.

50. McLaren L, Hawe P. Ecological perspectives in health research. J Epidemiol Community Health. 2005;59(1):6-14.

51. Garson G. Scales and standard measures [Internet]. 2009. Available from: http://tx. liberal.ntu.edu.tw/ purplewoo/Literature/!DataAnalysis/Reliability\%20Analysis.htm.

52. Kabiru CW, Ezeh A. Factors Associated with Sexual Abstinence among Adolescents in Four Sub-Saharan African Countries. Afr J Reprod Health. 2007:11(3):111-32.

53. Fatusi AO, Blum RW. Predictors of early sexual initiation among a nationally representative sample of Nigerian adolescents. BMC Public Health. 2008:8:136

54. Plummer ML, Wight D, Wamoyi J, Mshana G, Hayes RJ, Ross DA. Farming with Your Hoe in a Sack: Condom Attitudes, Access, and Use in Rural Tanzania. Stud Fam Plann. 2006;37(1):29-40.

55. Kraft P, Rise J, Sutton S, Røysamb E. Perceived difficulty in the theory of planned behaviour: Perceived behavioural control or affective attitude? Br J Soc Psychol. 2005:44(3):479-96.

56. Givaudan M, Van de Vijver FJR, Poortinga YH, Leenen I, Pick S. Effects of a School-Based Life Skills and HIV-Prevention Program for Adolescents in Mexican High Schools1. J Appl Soc Psychol. 2007;37(6):1141-62.

57. Albarracín D, Johnson BT, Fishbein M, Muellerleile PA. Theories of reasoned action and planned behavior as models of condom use: A meta-analysis. Psychol Bull. 2001;127(1):142-61.

\section{Submit your next manuscript to BioMed Central and take full advantage of:}

- Convenient online submission

- Thorough peer review

- No space constraints or color figure charges

- Immediate publication on acceptance

- Inclusion in PubMed, CAS, Scopus and Google Scholar

- Research which is freely available for redistribution 